\title{
Multiple functions of DDX3 RNA helicase in gene regulation, tumorigenesis, and viral infection
}

\author{
Yasuo Ariumi* \\ Ariumi Project Laboratory, Center for AIDS Research - International Research Center for Medical Sciences, Kumamoto University, Kumamoto, Japan
}

\author{
Edited by: \\ Masayuki Seki, Tohoku \\ Pharmaceutical University, Japan

\section{Reviewed by:} \\ Kaoru Tominaga, Jichi Medical \\ University, Japan \\ Victoria V. Lunyak, Buck Institute for \\ Research on Aging, USA

\section{*Correspondence:} \\ Yasuo Ariumi, Ariumi Project \\ Laboratory, Center for AIDS \\ Research - International Research \\ Center for Medical Sciences, \\ Kumamoto University, 2-2-1 Honjo, \\ Kumamoto 860-0811, Japan \\ e-mail: ariumi@kumamoto-u.ac.jp
}

\begin{abstract}
The DEAD-box RNA helicase DDX3 is a multifunctional protein involved in all aspects of RNA metabolism, including transcription, splicing, mRNA nuclear export, translation, RNA decay and ribosome biogenesis. In addition, DDX3 is also implicated in cell cycle regulation, apoptosis, Wnt- $\beta$-catenin signaling, tumorigenesis, and viral infection. Notably, recent studies suggest that DDX3 is a component of anti-viral innate immune signaling pathways. Indeed, DDX3 contributes to enhance the induction of anti-viral mediators, interferon (IFN) regulatory factor 3 and type I IFN. However, DDX3 seems to be an important target for several viruses, such as human immunodeficiency virus type 1 (HIV-1), hepatitis $\mathrm{C}$ virus (HCV), hepatitis B virus (HBV), and poxvirus. DDX3 interacts with HIV-1 Rev or HCV Core protein and modulates its function. At least, DDX3 is required for both HIV-1 and HCV replication. Therefore, DDX3 could be a novel therapeutic target for the development of drug against HIV-1 and HCV.
\end{abstract}

Keywords: DDX3, HCV, HIV-1, innate immunity, RNA helicases, stress granules, translation, tumor suppressor

\section{INTRODUCTION}

DDX3 belongs to the DEAD (D-E-A-D: Asp-Glu-Ala-Asp)-box RNA helicase family, which is an ATPase-dependent RNA helicase, is found in various organisms from yeast to human (Cordin et al., 2006; Linder and Lasko, 2006; Linder, 2008; Jankowsky, 2011). DDX3 has two homologs designated DDX3X (DBX) and DDX3Y (DBY), which were located on X and Y chromosomes, respectively (Lahn and Page, 1997; Park et al., 1998; Kim et al., 2001). DDX3X is ubiquitously expressed in most tissues, while the expression of DDX3Y protein is limited to the male germline (Ditton et al., 2004) and DDX3Y seems to be involved in male fertility (Leory et al., 1989; Mazeyrat et al., 1998; Foresta et al., 2000). DDX3 is involved in various RNA metabolism, including transcription, translation, RNA splicing, RNA transport, and RNA degradation (Chang and Liu, 2010; Schröder, 2010).

\section{REGULATION OF GENE EXPRESSION BY DDX3}

DDX3 regulates gene expression at different levels, such as transcription, splicing, mRNA export, and initiation of translation. First, DDX3 participates in transcriptional regulation of gene promoters. Indeed, DDX3 up-regulates the interferon (IFN) $\beta$ promoter (Soulat et al., 2008) and the $\mathrm{p} 21^{\text {wafl } 1 / \mathrm{cip} 1}$ promoter (Chao et al., 2006), respectively. DDX3 binds to the transcription factor Sp1 and enhance the $\mathrm{p} 21^{\text {waf1/cip1 }}$ promoter. On the other hand, DDX3 down-regulates the E-cadherin promoter (Botlagunta et al., 2008). In vivo association of DDX3 with the E-cadherin or the IFN $\beta$ promoter was demonstrated by chromatin immunoprecipitation assay. Second, DDX3 seems to contribute to splicing. DDX3 associates with spliced mRNAs in an exon junction complex (EJC)-dependent manner (Merz et al., 2007) and DDX3 contains C-terminal RS-like domain, which is stretches of protein sequence rich in arginine and serine residues and is found in splicing factors. Third, DDX3 contributes to the nuclear export of RNA. DDX3 shuttles between the cytoplasm and the nucleus (Owsianka and Patel, 1999; Yedavalli et al., 2004; Lai et al., 2008; Schröder et al., 2008). Accordingly, DDX3 interacts with two nuclear export shuttle protein: CRM1 as a receptor for protein containing the nuclear export signal (NES) and tip-associated protein (TAP) as the major receptor for mRNA export (Yedavalli et al., 2004; Lai et al., 2008). DDX3 interacts with CRM1 and functions in the human immunodeficiency virus type 1 (HIV-1) Rev-dependent nuclear export of HIV-1 mRNA (Yedavalli et al., 2004). Depletion of TAP resulted in nuclear accumulation of DDX3, suggesting DDX3 exports along with messenger ribonucleoprotein $(\mathrm{mRNP})$ to the cytoplasm via the TAP-mediated pathway (Lai et al., 2008).

Forth, DDX3 plays a role in translational regulation. DDX3 localizes in cytoplasmic stress granules under stress conditions (Lai et al., 2008; Shih et al., 2012), suggesting a role for DDX3 in translational control. DDX3 represses the cap-dependent translation by trapping eIF4E in a translationally inactive complex to block an interaction with eIF4G (Shih et al., 2008), indicating that DDX3 acts as a translational suppressor. Since depletion of DDX3 does not significantly affect general translation, DDX3 may be dispensable for general mRNA translation (Lai et al., 2008). Indeed, DDX3 associates with eIF4E together with several translation initiation factors, including eIF4a, eIF4G, eIF2a, eIF3, and poly(A)-binding protein $(\mathrm{PABP})$, and facilitates translation of mRNA containing structured 5' untranslated region (UTR; Lai et al., 2008; Shih et al., 2012; Soto-Rifo et al., 2012). In contrast, others reported that primary function for DDX3 is in protein translation via an interaction with eIF3 (Lee et al., 2008). Accordingly, DDX3 interacts with eIF3 and $40 \mathrm{~S}$ ribosome to support the assembly of functional $80 \mathrm{~S}$ ribosome (Geissler et al., 2012). The yeast DDX3 homolog, Ded1, also modulates translation by the formation of a translation initiation factor eIF4F-mRNA complex (Hilliker et al., 2011). Taken together, DDX3 modulates the protein translation. 
Finally, DDX3 interacts with Ago2, which is an essential factor in RNA interference (RNAi) pathway that cleaves target mRNA, and acts as an essential factor involved in RNAi pathway (Kasim et al., 2013).

\section{DDX3 IN CELL CYCLE REGULATION AND TUMORIGENESIS}

It has been indicated a role of DDX3 in cell cycle regulation, apoptosis, and tumorigenesis. In the temperature-sensitive DDX3 mutant hamster cell line tsET24 or the DDX3 knockdown cells, cell cycle was impedes transition from $\mathrm{G}_{1}$ to $\mathrm{S}$-phase (Fukumura et al., 2003; Lai et al., 2010). DDX3 enhances cyclin E1 during cell cycle by a translational regulation (Lai et al., 2010). On the other hand, DDX3 regulates the cell cycle by inhibiting cyclin D1 and causing cell cycle arrest (Chao et al., 2006). DDX3 is known to be phosphorylated by cyclin $\mathrm{B} / \mathrm{cdc} 2$ at threonine 204 to inhibit the function (Sekiguchi et al., 2007). Furthermore, DDX3 interacts with DDX5, which colocalizes with it in the cytoplasm through the phosphorylation of both proteins during $\mathrm{G}_{2} / \mathrm{M}$ phase of cell cycle (Choi and Lee, 2012), indicating the cell cycle-dependent regulation of DDX3 localization and the function. During mouse early embryonic development, DDX3 also regulates cell survival and cell cycle (Li et al., 2014b).

It has been indicated the oncogenic role of DDX3 in breast cancer (Botlagunta et al., 2008). Activation of DDX3 by benzo[a]pyrene diol epoxide (BPDE) present in tobacco smoke, can promote growth, proliferation and neoplastic transformation of breast epithelial cells. Consistent with this finding, overexpression of DDX3 induced an epithelial-mesenchymal-like transformation, exhibited increased motility and invasive properties, and formed colonies in soft agar assays. In addition, DDX3 is recruited to the E-cadherin promoter and represses the E-cadherin expression resulting the increased cell migration and metastasis (Botlagunta et al., 2008). Similarly, DDX3 also modulates cell adhesion, motility and cancer cell metastasis via Rac1-mediated signaling pathway (Chen et al., 2014). In fact, DDX3 knockdown reduces the cell migration, the invasive and metastatic activities, suggesting that DDX3 is required for metastasis and the oncogenic role of DDX3 in malignant cancers. The DDX3 knockdown also reduces the expression of levels of both Racl and $\beta$-catenin. DDX3 regulates Racl mRNA translation through an interaction with its $5^{\prime} \mathrm{UTR}$ and affects $\beta$-catenin protein stability in Rac1-dependent manner. In response to Wnt signaling, DDX3 binds to casein kinase (CK) $1 \varepsilon$ and stimulates CK1 1 mediated phosphorylation of the Wnt effector disheveled and thereby activates $\beta$-catenin (Cruciat et al., 2013), indicating a role of DDX3 as a regulator of Wnt- $\beta$-catenin network. Moreover, DDX3 may aid cancer progression by promoting increased levels of the transcription factor Snail (Sun et al., 2011). Snail is known to repress the expression of cellular adhesion proteins, leading to increased cell migration and metastasis of many types of cancer. In addition, recent study reported that positive DDX3 expression is significantly associated with large tumor size and high TNM (Tumor, Node, and Metastasis) stage, invasion, lymph node metastasis in gallbladder cancers (Miao et al., 2013), suggesting that DDX3 is a biomarker for metastasis and poor prognosis of gallbladder cancers. TNM classification is an anatomically based staging system that records the primary and regional nodal extent of the tumor and the absence or presence of metastases.

Hypoxia is a major characteristic of solid tumors and affects gene expression, which greatly impacts cellular and tumor tissue physiology particularly respiration and metabolism. Expression of hypoxia-responsive genes is predominantly regulated by hypoxia inducible factors (HIFs). DDX3 is aberrantly expressed in breast cancer cells ranging from weakly invasive to aggressive phenotypes (Botlagunta etal., 2011). HIF-1 binds to the DDX3 promoter and enhances the DDX3 expression (Botlagunta et al., 2011), indicating a DDX3 as a hypoxia inducible gene.

In contrast, DDX3 has been proposed to be a tumor suppressor (McGivern and Lemon, 2009). In fact, DDX3 inhibits colony formation in various cell lines and down-regulates cyclin D1 and up-regulates the p2 $1^{\text {wafl } / \text { cip } 1}$ promoter (Chao et al., 2006). DDX3 expression is deregulated in hepatocellular carcinoma (HCC; Chang etal., 2006; Chao et al., 2006). Loss of DDX3 leads to enhanced cell proliferation and reduced apoptosis (Chang et al., 2006). Similarly, loss of DDX3 by p53 inactivation promotes tumor malignancy via the MDM2/Slug/E-cadherin pathway and consequently results in poor patient outcome in non-small-cell lung cancer (Wu et al., 2014). In addition, DDX3 contributes to both antiapoptotic and proapoptotic actions. Death receptors are found to be capped by an antiapoptotic protein complex containing GSK3, DDX3 and cIAP-1 and DDX3 protects from apoptotic signaling (Sun et al., 2008). In contrast, DDX3 also associates with p53, increases p53 accumulation, and positively regulates DNA damage-induced apoptosis (Sun et al., 2013). Furthermore, reduced $\mathrm{p} 21^{\text {wafl/cip } 1}$ via alteration of p53-DDX3 pathway is associated with poor relapse-free survival in early stage human papillomavirus-associated lung cancer (Wu et al., 2011). Thus, p2 $1^{\text {wafl } 1 / \text { cip } 1}$ is considered to act as a tumor suppressor. Since low/negative DDX3 expression in tumor cells is significantly associated with aggressive clinical manifestations, low/negative expression of DDX3 might predict poor prognosis in oral cancer patients (Lee et al., 2014).

Altogether, DDX3 has both tumor suppression and oncogenic properties. This may reflect on the cell type used in their experiments. Further studies are necessary to clarify the potential role of DDX3 in cell growth regulation. These studies may shed a light on the development of drugs for chemotherapy against cancer and viral infection described below.

\section{DDX3 AS A TARGET OF VIRUSES}

DDX3 has been implicated in a target of several viruses, including hepatitis C virus (HCV), HIV-1, hepatitis B virus (HBV), West Nile virus (WNV), Japanese encephalitis virus, norovirus, pestivirus, vaccinia virus, and cytomegalovirus (Table 1). DDX3 is required for several RNA viral replication such as HCV and HIV1, while DDX3 restricts HBV replication. At least, DDX3 may be a therapeutic target for anti-viral drug against HCV and HIV-1.

\section{REQUIREMENT OF DDX3 IN HCV LIFE CYCLE}

Hepatitis $C$ virus is a causative agent of chronic hepatitis, which progresses to liver cirrhosis and HCC. HCV is an enveloped virus with a positive single-stranded $9.6 \mathrm{~kb}$ RNA genome, which encodes 
Table 1 | DDX3 as a target of viruses.

\begin{tabular}{llll}
\hline Virus & $\begin{array}{l}\text { Effect of DDX3 } \\
\text { on viral } \\
\text { replication }\end{array}$ & $\begin{array}{l}\text { Viral binding } \\
\text { protein }\end{array}$ & Cellular function \\
\hline HCV & Up-regulation & Core & Translational regulation \\
HIV-1 & Up-regulation & Rev & Nuclear export of mRNA \\
& & Tat & Translational regulation \\
HBV & Down-regulation & Pol & Inhibition of IFN induction \\
Vaccinia virus & $?$ & K7 & Inhibition of IFN induction \\
WNV & Up-regulation & $?$ & $?$ \\
\hline
\end{tabular}

DDX3 interacts with several RNA virus including hepatitis $C$ virus (HCV), human immunodeficiency virus type 1 (HIV-1), hepatitis $B$ virus (HBV), vaccinia virus, and West Nile virus (WNV). DDX3 is required for HCV, HIV-1, WNV replication, while DDX3 restricts $H B V$ replication. Furthermore, these viral proteins suppress the DDX3-mediated type I IFN induction though an interaction with DDX3.

a large polyprotein precursor of $\sim 3,000$ amino acid residues (Kato et al., 1990). This polyprotein is cleaved by a combination of the host and viral proteases into at least 10 proteins in the following order: core, envelope 1 (E1), E2, p7, non-structural 2 (NS2), NS3, NS4A, NS4B, NS5A, and NS5B (Hijikata et al., 1991, 1993). The HCV core protein is a viral structural protein, which forms the viral nucleocapsid, is targeted to lipid droplets (LDs). Recently, LDs have been found to be an important cytoplasmic organelle for HCV production (Miyanari et al., 2007). Budding is an essential step in the life cycle of enveloped viruses. HCV utilizes the endosomal sorting complex required for transport (ESCRT) system as the budding machinery (Ariumi et al., 2011b).

Several DEAD-box RNA helicases have been shown to interact with HCV proteins and regulate the HCV replication (Schröder, 2010; Upadya et al., 2014). DDX3 was identified as an HCV core-binding protein by yeast two-hybrid screening (Mamiya and Worman, 1999; Owsianka and Patel, 1999; You et al., 1999). HCV core protein was the first viral protein to be described as a DDX3-binding protein. HCV core binds to the C-terminal RSlike domain of DDX3 and the interaction is mediated by the $\mathrm{N}$-terminal 59 amino acid residues of HCV core. DDX3 and HCV core colocalized in distinct spots in the perinuclear region of the cytoplasm. However, these studies lack evidence regarding the functional relevance of the DDX3-HCV core interaction in HCV replication and the $\mathrm{HCV}$-associated liver diseases. Recent studies have demonstrated that DDX3 is required for HCV replication (Ariumi et al., 2007; Randall et al., 2007). The accumulation of both genome-length HCV RNA (HCV-O strain, genotype 1b; Ikeda et al., 2005) and its replicon RNA were significantly suppressed in the DDX3 knockdown cells. As well, HCV infection (JFH1 strain, genotype 2a; Wakita et al., 2005) was also suppressed in the DDX3 knockdown cells. Notably, HCV infection dynamically redistributes DDX3 to the HCV production site around LDs and colocalizes with HCV core (Figure 1; Ariumi et al., 2011a). However, the specific interactions between DDX3 and $\mathrm{HCV}$ core and the functional importance of these interactions for the HCV viral life cycle remain unclear. In this regard, Mutagenesis studies located a single amino acid in the $\mathrm{N}$-terminal domain of JFH1 core that when changed to alanine significantly abrogated this interaction. Surprisingly, this mutation did not alter infectious virus production and RNA replication, indicating that the core-DDX3 interaction is dispensable in the HCV life cycle (Angus etal., 2010). On the other hand, there is a contradictory report that the inhibition of $\mathrm{HCV}$ replication due to expression of the green fluorescent protein (GFP) fusion to $\mathrm{HCV}$ core protein residues $16-36$ can be reversed by overexpression of DDX3 (Sun et al., 2010). These results suggest that the protein interface on DDX3 that binds the HCV core protein is important for replicon maintenance. However, infection

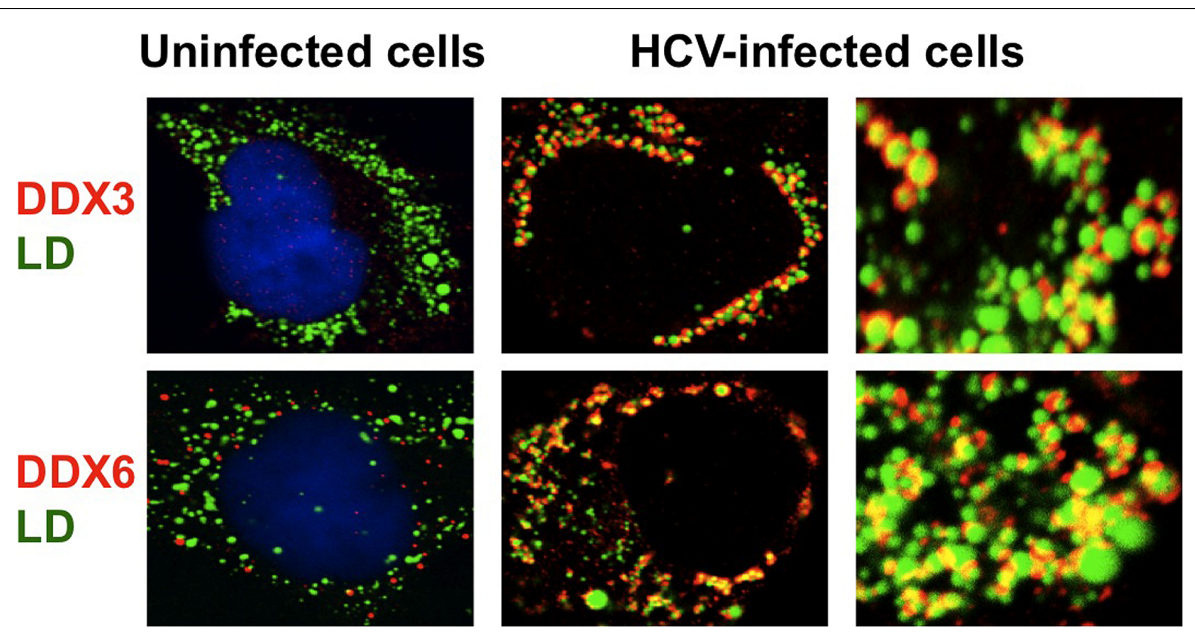

FIGURE 1 | Dynamic recruitment of DDX3 and DDX6 around lipid droplets (LDs) in response to HCV-JFH1 infection. Cells were fixed $60 \mathrm{~h}$ post-infection with HCV (JFH1 strain) and stained with either anti-DDX3 or anti-DDX6 antibody and were then visualized with Cy3 (red). Lipid droplets were specifically stained with fluorescent lipophilic dye
BODIPY 493/503 (green; Listenberger and Brown, 2007) and nuclei were stained with DAPI (blue), respectively. Images were visualized using confocal laser scanning microscopy. The two-color overlay images are also exhibited (merged). Colocalization is shown in yellow. High magnification image is also shown. 
of HuH-7 cells by HCV (JFH1) was not affected by expression of the GFP fusion protein. These results suggest that the role of DDX3 in HCV infection involves aspects of the viral life cycle that vary in importance between HCV genotypes. Therefore, the exact contribution of HCV core-DDX3 interaction remains to be determined.

In addition to DDX3, other DEAD-box RNA helicases DDX1, DDX5, and DDX6 have been involved in the HCV life cycle (Goh et al., 2004; Tingting et al., 2006; Jangra et al., 2010; Ariumi et al., 2011a; Kuroki et al., 2013). DDX1 bound to both the HCV 3'UTR and the HCV 5'UTR and DDX1 knockdown caused a marked reduction in the replication of subgenomic replicon RNA (Tingting et al., 2006). Furthermore, DDX5 was identified as an HCV NS5B RNA-dependent RNA polymerase-binding protein by yeast two-hybrid screening (Goh et al., 2004). Depletion of endogenous DDX5 correlated with a reduction in the transcription of negative strand HCV RNA, suggesting that DDX5 participates in the HCV RNA replication. Overexpression of HCV NS5B or the HCV infection redistributes DDX5 from the nucleus to the cytoplasm. Moreover, recent study reported that knockdown of DDX5 reduces HCV (JFH1) virus production in the supernatant, suggesting that DDX5 is important for a late stage of the HCV life cycle (Kuroki et al., 2013).

The microRNA miR122 and DDX6/Rck/p54, a microRNA effector, have been implicated in HCV replication (Jopling et al., 2005; Scheller et al., 2009; Jangra et al., 2010; Ariumi et al., 2011a). The liver-specific and abundant miR-122 interacts with the 5'UTR of the HCV RNA genome and facilitates the HCV replication (Jopling et al., 2005). DDX6 interacts with the eukaryotic initiation factor $4 \mathrm{E}$ (eIF-4E) to repress the translational activity of mRNP. Furthermore, DDX6 regulates the activity of the decapping enzymes DCP1 and DCP2 and interacts directly with Argonaute1 (Ago1) and Ago2 in the microRNA-induced silencing complex (miRISC) and is involved in RNA silencing. DDX6 predominantly localizes in the discrete cytoplasmic foci termed processing (P)body. Thus, the P-body may play a role in the translation repression and mRNA decay machinery (Parker and Sheth, 2007; Beckham and Parker, 2008). The knockdown of DDX6 was found to reduce the accumulation of intracellular HCV RNA and infectious HCV production, indicating that DDX6 is essential for the HCV RNA replication (Scheller et al., 2009; Jangra et al., 2010; Ariumi et al., 2011a). Notably, HCV (JFH1) infection disrupts the P-body formation of DDX3, DDX6, Lsm1, Xrn1, PATL1, and Ago2 and dynamically redistributes them to the HCV production site around LDs (Figure 2; Ariumi et al., 2011a), indicating that HCV hijacks the P-body components around LDs and regulates the HCV replication and translation. Recent studies suggested that DDX3 is also required for WNV, Japanese encephalitis virus, norovirus, and pestivirus (Vashist et al., 2012; Chahar et al., 2013; Jefferson et al., 2014; Li et al., 2014a; Tsai and Lloyd, 2014). Similarly, P-body components LSM1, GW182, DDX3, DDX6, and XRN1 are also recruited to $\mathrm{WNV}$ replication sites and positively regulate viral replication (Chahar et al., 2013).

On the other hand, recent studies have suggested a potential role of DDX3 and DDX5 in the pathogenesis of HCV-related liver diseases. DDX3 expression is deregulated in HCC (Chang et al., 2006; Chao et al., 2006) and single-nucleotide polymorphisms were identified in the DDX5 genes that were associated with an increased risk of advanced fibrosis in patients with chronic hepatitis C (Huang et al., 2006). DDX3 has been proposed to be a tumor suppressor (McGivern and Lemon, 2009). In fact, DDX3 inhibits colony formation in various cell lines, including human hepatoma $\mathrm{HuH}-7$, and up-regulates the $\mathrm{p} 21^{\text {waf1/cip } 1}$ promoter (Chao et al., 2006). Therefore, HCV core protein might overcome the DDX3-mediated cell growth arrest and down-regulate $\mathrm{p} 21^{\text {waf1/cip1 }}$ through an interaction with DDX3, and it might be involved in the development of HCC.

\section{DDX3 IS ESSENTIAL FOR HIV-1 REPLICATION}

Human immunodeficiency virus type 1 is the causative agent of acquired immune deficiency syndrome (AIDS). HIV-1 is a retrovirus with a positive strand RNA genome of $9 \mathrm{~kb}$ which encodes nine polypeptides, structural proteins, Gag (group specific antigen), Pol (polymerase) and Env (envelope), the accessory proteins, Vif, Vpu, Vpr, and Nef, and the regulatory proteins, Tat and Rev. The gene expression of HIV-1 is regulated transcriptionally by Tat through its binding to a nascent viral trans-activation responsive (TAR) RNA (Berkhout et al., 1989; Jeang et al., 1999),

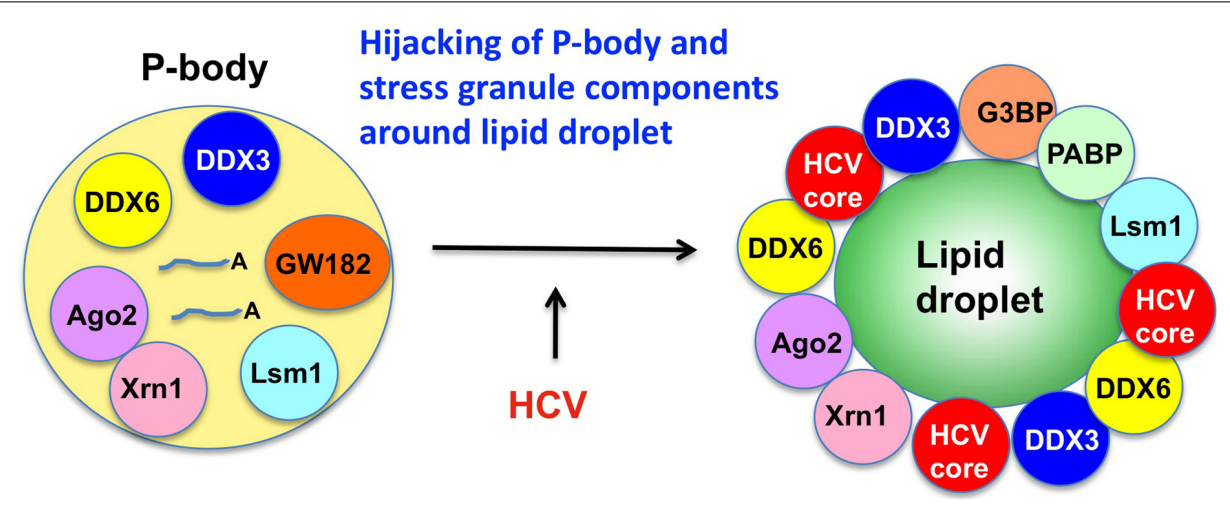

FIGURE 2 | Hijacking of P-body components around LD by HCV. HCV disrupts the P-body and hijacks the P-body components including DDX3, DDX6, Ago2, Xrn1, and Lsm1 around LD, an HCV production site. 
and post-transcriptionally by Rev through its association with Rev-responsive element (RRE) in the env gene (Hope and Pomerantz, 1995; Pollard and Malim, 1998; Cullen, 2003). Since the intron-containing host RNA cannot leave the nucleus before it is completely spliced, HIV-1 needs to evade host surveillance system to export unspliced or partially spliced viral RNA into cytoplasm and produce HIV-1 structural proteins and accessory proteins. For this, Rev contains a leucine-rich NES that recruits nuclear export receptor CRM1 (Hope and Pomerantz, 1995; Pollard and Malim, 1998; Cullen, 2003). Upon binding to the RRE together with the GTP-bound form of Ran (Ran-GTP), CRM1 forms the nuclear export complex and Rev-CRM1-RRE-Ran-GTP complex exports unspliced or partially spliced HIV-1 RNA from the nucleus to the cytoplasm.

Several viruses are known to carry their own RNA helicases to facilitate the replication of their viral genome, including $\mathrm{HCV}$, flavivirus, severe acute respiratory syndrome (SARS) coronavirus, rubella virus, and alphavirus, however, HIV-1 does not encode own RNA helicase (Utama et al., 2000; Kwong et al., 2005). Thus, host RNA helicases may be involved in HIV-1 replication at multiple stages, including the reverse transcription of HIV-1 RNA, HIV-1 mRNA transcription, the nucleus-to-cytoplasm transport of HIV-1 mRNA, and HIV-1 RNA packaging (Cochrane et al., 2006; Lorgeoux et al., 2012).

In fact, DDX3 was first found to involve in the Rev-dependent nuclear export of unspliced and partially spliced HIV-1 RNAs (Figure 3; Yedavalli etal., 2004). Over-expression of DDX3 enhanced the Rev-dependent nuclear export function. Conversely, knockdown of DDX3 or expression of dominant negative mutant of DDX3 significantly suppressed the Rev function as well as HIV-1 replication (Yedavalli et al., 2004; Ishaq et al., 2008). Rev is coimmunoprecipitated with DDX3. DDX3 is a nucleo-cytoplasmic shuttling protein, which binds CRM1 and localizes to nuclear membrane pores.

In addition to DDX3, another DEAD-box RNA helicase DDX1 also associates with Rev and promotes the Rev-dependent RNA nuclear export function (Fang et al., 2004). DDX1 interacts with Rev via the N-terminal domain, suggesting a role of DDX1 in initial complex assembly. DDX1 promotes Rev oligomerization on the RRE through this interaction (Robertson-Anderson et al., 2011). Thus, DDX1 and DDX3 act sequentially in the Revdependent RNA nuclear export. DDX1 first binds to Rev and promotes Rev oligomerization on the RRE. Then, the oligomerized Rev recruits the CRM1/DDX3 complex that subsequently exports the RRE-containing HIV-1 RNAs into the cytoplasm (Lorgeoux etal., 2012). In addition to DDX1 and DDX3, we and other group recently reported that other RNA helicases, including DDX5, DDX17, DDX21, DHX36, DDX47, DDX56, and RNA helicase A (RHA) associate with the Rev-dependent nuclear export function (Figure 3; Li et al., 1999; Naji et al., 2012; Yasuda-Inoue et al., 2013a; Zhou et al., 2013). Furthermore, DDX3 interacts with DDX5 and synergistically enhances the Rev-dependent nuclear export. As well, combination of other distinct DDX RNA helicases such as DDX1 and DDX3 also synergistically facilitates the Rev function (Yasuda-Inoue et al., 2013a) suggesting that a set of distinct Rev-interacting DEAD-box RNA helicases cooperate to modulate the HIV-1 Rev function.

On the other hand, HIV-1 Tat activates the HIV-1 RNA synthesis. Tat binds to the TAR RNA and recruits several host factors including p300/CREB-binding protein (p300/CBP), p300/CBPassociated factor (PCAF), SWI/SNF chromatin-remodeling complex, and positive transcription elongation factor $\mathrm{b}(\mathrm{P}-\mathrm{TEFb})$ to stimulate both transcription initiation and elongation (Jeang et al., 1999; Ariumi et al., 2006; Lorgeoux et al., 2012). P-TEFb

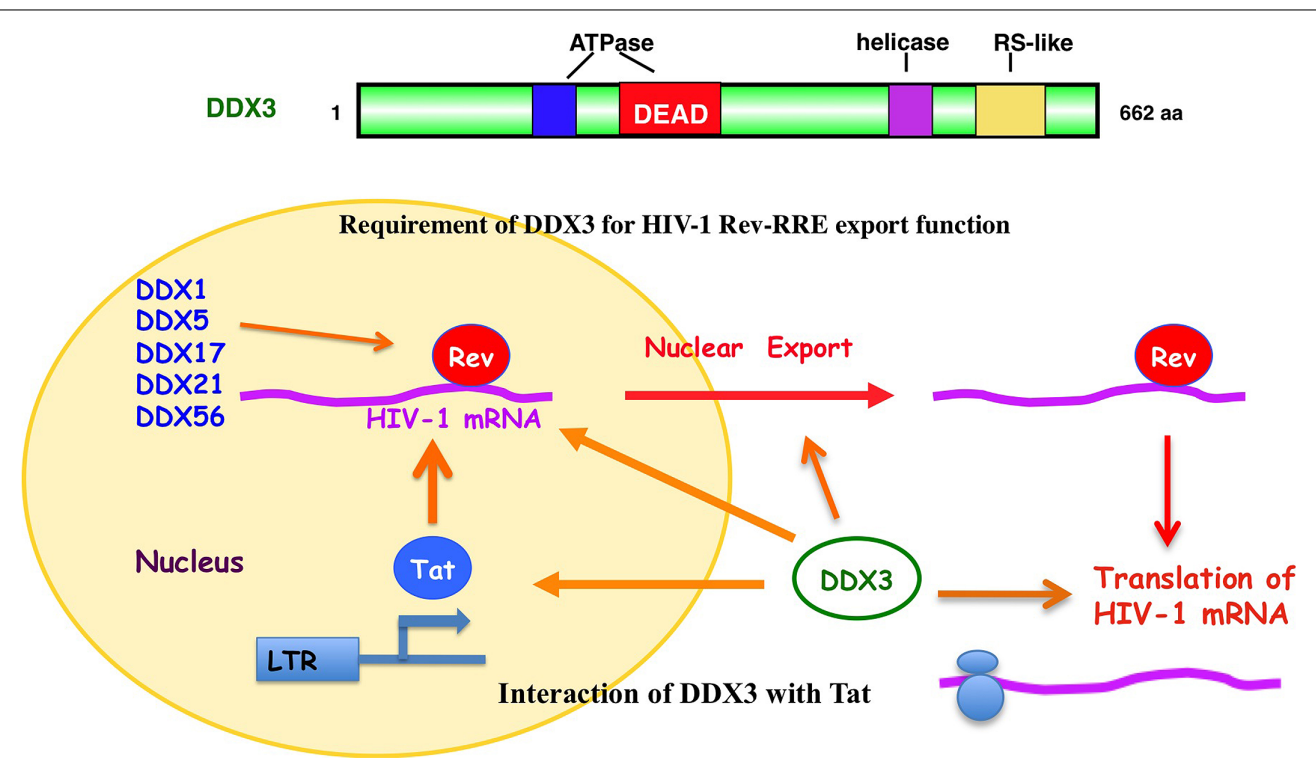

FIGURE 3 | Role of DDX3 in the HIV-1 gene expression. DDX3 interacts with HIV-1 Rev and facilitates the Rev-dependent nuclear export of HIV-1 mRNA. DDX3 interacts with Tat and contributes to the translation of HIV-1 mRNA. Other DEAD-box RNA helicases, including DDX1, DDX5, DDX17, DDX21, and DDX56, also interact with HIV-1 Rev and facilitate its function. 
contains cyclin T1 and cyclin-dependent kinase 9 (CDK9). CDK9 hyperphosphorylates the C-terminal domain (CTD) of RNA Pol II and activates transcription elongation. The Werner syndrome (WRN) helicase and RHA were reported to act as co-factors of Tat and enhance the HIV-1 gene expression (Fujii et al., 2001; Sharma etal., 2007). In addition to WRN and RHA, DDX3 interacts with Tat (Figure 3; Lai et al., 2013; Yasuda-Inoue et al., 2013b). Tat is partially targeted to cytoplasmic stress granules upon DDX3 overexpression or cell stress conditions, suggesting a potential role of Tat/DDX3 complex in translation. Accordingly, Tat remains associated with translating mRNAs and facilitates translation of mRNAs containing the HIV-1 $5^{\prime}$ UTR. In this regard, DDX3 is essential for translation of HIV-1 genomic RNA (gRNA; Figure 3; Soto-Rifo et al., 2012). DDX3 directly binds to the HIV-1 5'UTR and interacts with eIF4G and PABP but lacking the major cap-binding proteins eIF4E in large cytoplasmic RNA granules (Soto-Rifo et al., 2013), indicating that DDX3 promotes the HIV-1 gRNA translation initiation in an eIF4E-independent manner.

Both HIV-1 and HCV have been shown to utilize DDX3 as a cofactor for viral genome replication. Therefore, DDX3 could be an important therapeutic target for development of anti-viral drug (Kwong et al., 2005). Indeed, small molecule inhibitors were used to inhibit ATPase activity of DDX3 with anti-HIV-1 activity (Maga et al., 2008, 2011; Yedavalli et al., 2008; Radi et al., 2012).

\section{DDX3 RESTRICTS HBV REPLICATION}

Hepatitis $B$ virus is also the causative agent of chronic hepatitis, which progresses to liver cirrhosis and HCC worldwide. HBV belongs to hepadnavirus family and contains a small partially double-stranded circular DNA genome of $3.2 \mathrm{~kb}$. Even though $\mathrm{HBV}$ is a DNA virus, $\mathrm{HBV}$ replicates its DNA genome via reverse transcription. Upon HBV infection, the HBV DNA is converted into covalently closed circular DNA (cccDNA) as the template for the viral transcription. Pregenomic RNA (pgRNA) of $3.5 \mathrm{~kb}$ is selectively packaged into nucleocapsid together with HBV Pol. The pgRNA is reverse transcribed by HBV Pol to generate relaxed circular (RC) DNA. The HBV reverse transcription occurs entirely within nucleocapsid following encapsidation.

Recently, it was shown that DDX3 specifically binds to the HBV $\mathrm{Pol}$ and is incorporated into nucleocapsid together with HBV Pol (Wang et al., 2009). However, unlike HIV-1 and HCV replication, which is enhanced by DDX3 (Yedavalli et al., 2004; Ariumi et al., 2007; Randall et al., 2007), HBV reverse transcription was inhibited by DDX3. In addition, recent study reported that DDX3 suppresses transcription from HBV promoter (Ko et al., 2014). The helicase activity is dispensable for this DDX3-mediated transcription suppression. Thus, DDX3 is identified as a new host restriction factor for HBV.

\section{ROLE OF DDX3 IN ANTI-VIRAL INNATE IMMUNITY}

Viral infection triggers host innate immune responses through activation of the transcription factors NF- $\mathrm{\kappa B}$ and IFN regulatory factor (IRF)-3 leading to type I IFN production and anti-viral state in mammalian cells (Gale and Foy, 2005; Saito and Gale, 2007). Similar to NF-кB, IRF-3 is retained in cytoplasm in uninfected cells. After viral infection, IRF-3 is phosphorylated by IKK $\varepsilon$ and
TBK1 and the phosphorylated IRF-3 then homodimerizes and translocates into the nucleus to activate type I IFN. Type I IFNs, such as IFN- $\alpha$ and IFN- $\beta$ are essential for immune defense against viruses. These IFNs activate the JAK-STAT pathway to induce the IFN-stimulated genes (ISGs), which impact immune enhancing and antiviral action of host cells.

Double-stranded RNA (dsRNA) produced during viral replication is recognized by the host cell as pathogen-associated molecular patterns (PAMPs) by two major pathogen recognition receptor (PRR) proteins: the Toll-like receptors (TLRs; Akira and Takeda, 2004) and DEAD-box RNA helicases RIG-I and Mda5 (Andrejeva et al., 2004; Yoneyama et al., 2004). RIG-I contains two $\mathrm{N}$-terminal caspase activation and recruitment domains (CARD) and a C-terminal RNA helicase domain that binds to dsRNA. Binding viral RNA to RIG-I lead to a conformational change that allows to interact with the RIG-I/Mda5 adaptor IPS1/MAVS/Cardif/VISA (Kawai et al., 2005; Meylan et al., 2005; Seth etal., 2005; Xu etal., 2005) leading to the activation of IRF-3 and NF-кB. Notably, RIG-I and Mda5 distinguish RNA viruses and are critical for host antiviral responses (Kato et al., 2006). RIG-I is essential for the production of IFN in response to RNA viruses including paramyxoviruses, influenza virus and Japanese encephalitis virus, while Mda5 is critical for picornavirus detection.

DDX3 was recently reported to be a component of anti-viral innate immune signaling pathway leading to type I IFN (Figure 4; Schröder et al., 2008; Soulat et al., 2008; Gu et al., 2013). Indeed, DDX3 contributes to enhance the induction of anti-viral mediators, IRF3 and type I IFN. DDX3 up-regulates the IFN- $\beta$ induction through an interaction with IKK 8 (Figure 4; Schröder et al., 2008; Gu et al., 2013) or TBK1 (Soulat et al., 2008). Phosphorylation of

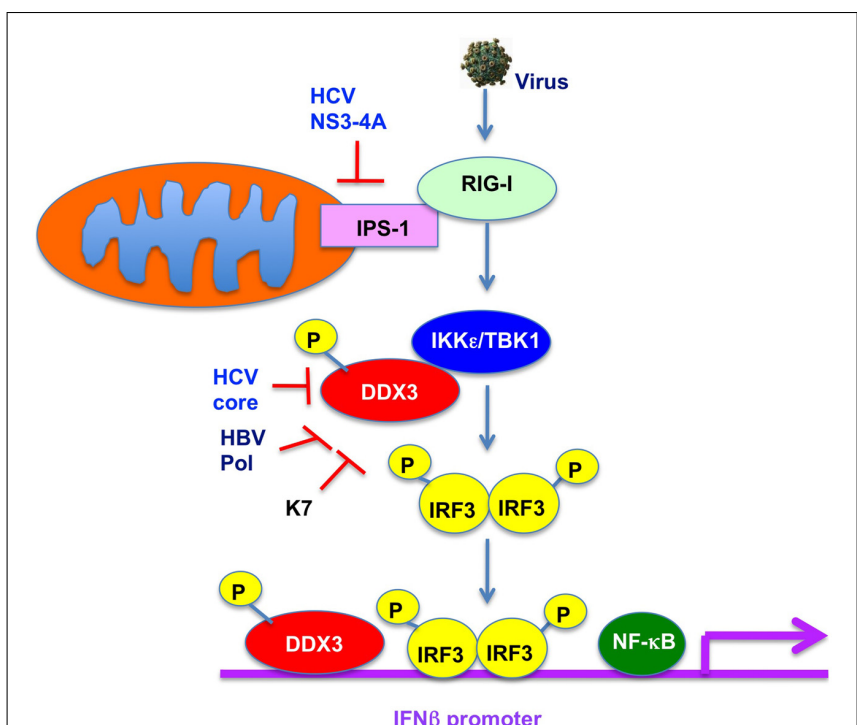

FIGURE 4 | Role of DDX3 in anti-viral innate immunity. DDX3 interacts with TBK1/IKK $\varepsilon$ and is phosphorylated by TBK $1 / / K K_{\varepsilon}$. TBK1/IKK $\varepsilon$ then phosphorylates IRF3 and translocates into the nucleus leading to the activation of IFN $\beta$ promoter. DDX 3 is also recruited on the IFN $\beta$ promoter and enhances the IFN $\beta$ production. In contrast, HCV core, HBV Pol, or vaccinia virus $K 7$ interacts with DDX3 and suppresses the IFN $\beta$ induction. 
DDX3 at serine 102 by IKK $\varepsilon$ was required for the recruitment of IRF-3 into the complex. Both IKKE and TBK1 are IRF-3-activating kinase to leading the NF- $\mathrm{B}$ and IFN induction. Furthermore, DDX3 is recruited to the IFN $\beta$ promoter (Figure 4; Soulat et al., 2008), suggesting that DDX3 acts as a transcriptional regulator. In addition, DDX3 also forms a complex with RIG-I and Mda5 and binds to IPS- 1 to facilitate IFN $\beta$ induction (Oshiumi et al., 2010b), suggesting that DDX3 acts as a viral RNA sensor and a scaffolding adaptor to link of viral RNA with the IPS-1 complex.

In contrast, viruses must overcome the host anti-viral innate immunity. HCV NS3-4A protease cleaves IPS-1/Cardif to block IFN $\beta$ induction (Figure 4; Meylan et al., 2005) In addition, HCV core protein can disrupt the DDX3-IPS-1/MAVS/Cardif/VISA interaction and act as a viral immune evasion protein preventing IFN $\beta$ induction (Figure 4; Oshiumi et al., 2010a). Furthermore, DDX3 is known to bind to HBV Pol and restrict the HBV replication (Wang et al., 2009). Conversely, HBV Pol acts as a viral immune evasion protein by disrupting the interaction of DDX3 with TBK1/ IKKE (Figure 4; Wang and Ryu, 2010; Yu et al., 2010). Similarly, vaccinia virus K7 protein targets DDX3 (Schröder et al., 2008; Kalverda et al., 2009; Oda et al., 2009) and inhibits the IFN $\beta$ induction by preventing TBK1/ IKK $\varepsilon$-mediated IRF activation (Figure 4; Schröder et al., 2008). Moreover, DDX3 contributes the DNA sensor ZBP1/DAI-dependent IFN response after human cytomegalovirus infection (DeFilippis et al., 2010).

In conclusion, DDX3 participates in anti-viral innate immune signaling pathway leading to type I IFN induction. In contrast, viruses must target DDX3 and evolve mechanisms to overcome this host immune system. Indeed, several RNA viruses sequester and utilize DDX3 for their viral replication and prevent IFN induction.

\section{ACKNOWLEDGMENTS}

I thank Ms. Noriko Tokushige for secretarial assistance. This work was supported by a Grant-in-Aid for Scientific Research from the Japan Society for the Promotion of Science (JSPS), by a Grant-inAid for Research on Hepatitis from the Ministry of Health, Labor, and Welfare of Japan, and by Takeda Science Foundation.

\section{REFERENCES}

Akira, S., and Takeda, K. (2004). Toll-like receptor signaling. Nat. Rev. Immunol. 4, 499-511. doi: 10.1038/nri1391

Andrejeva, J., Child, K. S., Young, D. F., Carlos, T. S., Stocks, N., Goodbourn, S., etal. (2004). The V protein of paramyxoviruses bind the IFNinducible RNA helicase, mda-5, and inhibit its activation of the IFN- promoter. Proc. Natl. Acad. Sci. U.S.A. 101, 17264-17269. doi: 10.1073/pnas.04076 39101

Angus, A. G., Dalrymple, D., Boulant, S., McGivern, D. R., Clayton, R. F., Scott, M. J., et al. (2010). Requirement of cellular DDX3 for hepatitis $\mathrm{C}$ virus replication is unrelated to its interaction with the viral core protein. J. Gen. Virol. 91, 122-132. doi: 10.1099/vir.0.015909-0

Ariumi, Y., Kuroki, M., Abe, K., Dansako, H., Ikeda, M., Wakita, T., et al. (2007). DDX3 DEAD-box RNA helicase is required for hepatitis $\mathrm{C}$ virus RNA replication. J. Virol. 81, 13922-139226. doi: 10.1128/JVI.01517-07

Ariumi, Y., Kuroki, M., Kushima, Y., Osugi, K., Hijikata, M., Maki, M., et al. (2011a). Hepatitis C virus hijacks P-body and stress granule components around lipid droplets. J. Virol. 85, 6882-6892. doi: 10.1128/JVI02418-10

Ariumi, Y., Kuroki, M., Maki, M., Ikeda, M., Dansako, H., Wakita, T., et al. (2011b). The ESCRT system is required for hepatitis $\mathrm{C}$ virus production. PLoS ONE 6:e14517. doi: 10.1371/journal.pone.0014517
Ariumi, Y., Serhan, F., Turelli, P., Telenti, A., and Trono, D. (2006). The integrase interactor 1 (INI1) proteins facilitate Tat-mediated human immunodeficiency virus type 1 transcription. Retrovirology 3, 47. doi: 10.1186/1742-4690-3-47

Beckham, C. J., and Parker, R. (2008). P bodies, stress granules, and viral life cycle. Cell Host Microbe 3, 206-212. doi: 10.1016/j.chom.2008.03.004

Berkhout, B., Silverman, R. H., and Jeang, K. T. (1989). Tat trans-activates the human immunodeficiency virus through a nascent RNA target. Cell 59, 273-282. doi: 10.1016/0092-8674(89)90289-4

Botlagunta, M., Krishnamachary, B., Vesuna, F., Winnard, P. T. Jr., Bol, G. M., Patel, A. H., et al. (2011). Expression of DDX3 is directly modulated by hypoxia inducible factor-1 alpha in breast epithelial cells. PLOS ONE 6:e17563. doi: 10.1371/journal.pone.0017563

Botlagunta, M., Vesuna, F., Mironchik, Y., Raman, A., Lisok, A., Winnard, P. Jr., et al. (2008). Oncogenic role of DDX3 in breast cancer biogenesis. Oncogene 27, 3912-3922. doi: 10.1038/onc.2008.33

Chahar, H. S., Chen, S., and Manjunath, N. (2013). P-body components LSM1, GW182, DDX3, DDX6 and XRN1 are recruited to WNV replication sites and positively regulate viral replication. Virology 436, 1-7. doi: 10.1016/j.virol.2012.09.041

Chang, P. C., Chi, C. W., Chau, G. Y., Li, F. Y., Tsai, Y. H., Wu, J. C., et al. (2006). DDX3, a DEAD box RNA helicase, is deregulated in hepatitis virus-associated hepatocellular carcinoma and is involved in cell growth control. Oncogene 25, 1991-2003. doi: 10.1038/sj.onc.1209239

Chang, T. C., and Liu, W. S. (2010). The molecular evolution of PL10 homologs. BMC Evol. Biol. 10:127. doi: 10.1186/1471-2148-10-127

Chao, C. H., Chen, C. M., Cheng, P. L., Shih, J. W., Tsou, A. P., and Lee, Y. H. (2006). DDX3, a DEAD box RNA helicase with tumor growth-suppressive property and transcriptional regulation activity of the $\mathrm{p} 21$ wafl/cip 1 promoter, is a candidate tumor suppressor. Cancer Res. 66, 6579-6588. doi: 10.1158/0008-5472.CAN-052415

Chen, H. H., Yu, H. I., Cho, W. C., and Tarn, W. Y. (2014). DDX3 modulates cell adhesion and mobility and cancer cell metastasis via Racl-mediated signaling pathway. Oncogene doi: 10.1038/onc.2014.190 [Epub ahead of print].

Choi, Y. J., and Lee, S. G. (2012). The DEAD-box RNA helicase DDX3 interacts with DDX5, co-localizes with it in the cytoplasm during the G2/M phase of the cycle, and affects its shuttling during mRNP export. J. Cell Biochem. 113, 985-996. doi: $10.1002 /$ jcb. 23428

Cochrane, A. W., McNally, M. T., and Mouland, A. J. (2006). The retrovirus RNA trafficking granule: from birth to maturity. Retrovirology 3 , 18. doi: 10.1186/17424690-3-18

Cordin, O., Banroques, J., Tanner, N. K., and Linder, P. (2006). The DEAD-box protein family of RNA helicases. Gene 367, 17-37. doi: 10.1016/j.gene.2005.10.019 Cruciat, C. M., Dolde, C., de Groot, R. E., Ohkawara, B., Reinhard, C., Korswagen, H. C., et al. (2013). RNA helicase DDX3 is a regulatory subunit of casein kinase 1 in Wnt- $\beta$-catenin signaling. Science 339, 1436-1441. doi: 10.1126/science.12 31499

Cullen, B. R. (2003). Nuclear mRNA export: insights from virology. Trends Biochem. Sci. 28, 419-424. doi: 10.1016/S0968-0004(03)00142-7

DeFilippis, V. R., Alvarado, D., Sali, T., Rothenburg, S., and Früh, K. (2010). Human cytomegalovirus induces the interferon response via the DNA sensor ZBP1. J. Virol. 84, 585-598. doi: 10.1128/JVI.01748-09

Ditton, H. J., Zimmer, J., Kamp, C., Rajpert-De Meyts, E., and Vogt, P. H. (2004). The AZFa gene DBY (DDX3Y) is widely transcribed but the protein is limited to the male germ cells by translation control. Hum. Mol. Genet. 13, 2333-2341. doi: 10.1093/hmg/ddh240

Fang, J., Kubota, S., Yang, B., Zhou, N., Zhang, H., Godbout, R., et al. (2004). A DEAD box protein facilitates HIV-1 replication as a cellular co-factor of Rev. Virology 330, 471-480. doi: 10.1016/j.virol.2004.09.039

Foresta, C., Ferlin, A., and More, E. (2000). Deletion and expression analysis of AZFa genes on the human chromosome revealed a major role for DBY in male infertility. Hum. Mol. Genet. 9, 1161-1169. doi: 10.1093/hmg/9.8.1161

Fujii, R., Okamoto, M., Aratani, S., Oishi, T., Ohshima, T., Taira, K., et al. (2001). A role of RNA helicase A in cis-acting transactivation response element-mediated transcriptional regulation of human immunodeficiency virus type 1. J. Biol. Chem. 276, 5445-5451. doi: 10.1074/jbc.M006892200

Fukumura, J., Noguchi, E., Sekiguchi, T., and Nishimoto, T. (2003). A temperaturesensitive mutant of the mammalian RNA helicase, DEAD-box isoform, DBX, defective in the transition from G1 to S phase. J. Biochem. 134, 71-82. doi: $10.1093 / \mathrm{jb} / \mathrm{mvg} 126$ 
Gale, M. Jr., and Foy, E. M. (2005). Evasion of intracellular host defence by hepatitis C virus. Nature 436, 939-945. doi: 10.1038/nature04078

Geissler, R., Golbik, R. P., and Behrens, S. E. (2012). The DEAD-box helicase DDX3 supports the assembly of functional 80 S ribosomes. Nucleic Acids Res. 40 , 4998-5011. doi: 10.1093/nar/gks070

Goh, P. Y., Tan, Y. J., Lim, S. P., Tan, Y. H., Lim, S. G., Fuller-Pace, F., et al. (2004) Cellular RNA helicase $\mathrm{p} 68$ relocalization and interaction with the hepatitis $\mathrm{C}$ virus (HCV) NS5B protein and the potential role of p68 in HCV RNA replication. J. Virol. 78, 5288-5298. doi: 10.1128/JVI.7810.5288-5298.2004

Gu, L., Fullam, A., Brennan, R., and Schröder, M. (2013). Human DEAD box helicase 3 couples IкB kinase $\varepsilon$ to interferon regulatory factor 3 activation. Mol. Cell. Biol. 33, 2004-2015. doi: 10.1128/MCB.01603-12

Hijikata, M., Kato, N., Ootsuyama, Y., Nakagawa, M., and Shimotohno, K. (1991). Gene mapping of the putative structural region of the hepatitis $\mathrm{C}$ virus genome by in vitro processing analysis. Proc. Natl. Acad. Sci. U.S.A. 88, 5547-5551. doi: $10.1073 /$ pnas.88.13.5547

Hijikata, M., Mizushima, H., Tanji, Y., Komoda, Y., Hirowatari, Y., Akagi, T., et al (1993). Proteolytic processing and membrane association of putative nonstructural proteins of hepatitis C virus. Proc. Natl. Acad. Sci. U.S.A. 90, 10773-10777. doi: 10.1073/pnas.90.22.10773

Hilliker, A., Gao, Z., Jankowsky, E., and Parker, R. (2011). The DEAD-box protein Ded1 modulates translation by the formation and resolution of an eIF4F-mRNA complex. Mol. Cell 43, 962-972. doi: 10.1016/j.molcel.2011. 08.008

Hope, T. J., and Pomerantz, R. J. (1995). The human immunodeficiency virus type 1 Rev protein: a pivotal protein in the viral life cycle. Curr. Top. Microbiol. Immunol 193, 91-105. doi: 10.1007/978-3-642-78929-8_5

Huang, H., Shiffman, M. L., Cheung, R. C., Layden, T. J., Friedman, S., Abar, O. T. et al. (2006). Identification of two gene variants associated with risk of advanced fibrosis in patients with chronic hepatitis C. Gastroenterology 130, 1679-1687. doi: 10.1053/j.gastro.2006.02.032

Ikeda, M., Abe, K., Dansako, H., Nakamura, T., Naka, K, and Kato, N. (2005). Efficient replication of a full-length hepatitis $\mathrm{C}$ virus genome, strain $\mathrm{O}$, in cell culture, and development of a luciferase reporter system. Biochem. Biophys. Res. Commun. 329, 1350-1359. doi: 10.1016/j.bbrc.2005.02.138

Ishaq, M., Hu, J., Wu, X., Fu, Q., Yang, Y., Liu, Q., et al. (2008). Knockdown of cellular RNA helicase DDX3 by short hairpin RNAs suppresses HIV-1 replication without inducing apoptosis. Mol. Biotechnol. 39, 231-238. doi: 10.1007/s12033008-9040-0

Jangra, R. K., Yi, M., and Lemon, S. M. (2010). DDX6 (Rck/p54) is required for efficient hepatitis $\mathrm{C}$ virus replication but not for internal ribosome entry sitedirected translation. J. Virol. 84, 6810-6824. doi: 10.1128/jvi.00397-10

Jankowsky, E. (2011). RNA helicases at work: binding and rearranging. Trends Biochem. Sci. 36, 19-29. doi: 10.1016/j.tibs.2010.07.008

Jeang, K. T., Xiao, H., and Rich, E. A. (1999). Multifaceted activities of the HIV1 transactivator of transcription, Tat. J. Biol. Chem. 274, 28837-28840. doi 10.1074/jbc.274.41.28837

Jefferson, M., Donaszi-Ivanov, A., Pollen, S., Dalmary, T., Saalbach, G., and Powell, P. P. (2014). Host factors interacting with the pestivirus $\mathrm{N}$ terminal protease, Npro are components of the ribonucleoprotein complex. J. Virol. 88, 10340-1053. doi: 10.1128/JVI.00984-14

Jopling, C. L., Yi, M., Lancaster, A. M., Lemon, S. M., and Sarnow, P. (2005). Modulation of hepatitis C virus RNA abundance by a liver-specific microRNA. Science 309, 1577-1581. doi: 10.1126/science.1113329

Kalverda, A. P., Thompson, G. S., Vogel, A., Schröder, M., Bowie, A. G., Khan, A. R., et al. (2009). Poxvirus K7 protein adopts a Bcl-2 fold: biochemical mapping of its interactions with human DEAD box RNA helicase DDX3. J. Mol. Biol. 385 , 843-853. doi: 10.1016/j.jmb.2008.09.048

Kasim, V., Wu, S., Taira, K., and Miyagishi, M. (2013). Determination of the role of DDX3 a factor involved in mammalian RNAi pathway using an shRNA-expression library. PLoS ONE 8:e59445. doi: 10.1371/journal.pone.0059445

Kato, N., Hijikata, M., Ootsuyama, Y., Nakagawa, M., Ohkoshi, S., and Shimotohno, K. (1990). Molecular cloning of the human hepatitis $C$ virus genome from Japanese patients with non-A, non-B hepatitis. Proc. Natl. Acad. Sci. U.S.A. 87, 9524-9528. doi: 10.1073/pnas.87.24.9524

Kato, N., Takeuchi, O., Sato, S., Yoneyama, M., Yamamoto, M., Matsui, K., et al. (2006). Differential roles of MDA5 and RIG-I helicases in the recognition of RNA viruses. Nature 441, 101-105. doi: 10.1038/nature04734
Kawai, T., Takahashi, K., Sato, S., Coban, C., Kumar, H., Kato, H., et al. (2005). IPS1 , an adaptor triggering RIG-I- and Mda5-mediated type I interferon induction. Nat. Immunol. 6, 981-988. doi: 10.1038/ni1243

Kim, Y. S., Lee, S. G., Park, S. H., and Song, K. (2001). Gene structure of the human DDX3 and chromosome mapping of its related sequences. Mol. Cells 12, 209-214.

Ko, C., Lee, S., Windisch, M. P., and Ryu, W. S. (2014). DDX3 DEAD-box RNA helicase is a host factor that restricts hepatitis $\mathrm{B}$ virus replication at the transcriptional level. J. Virol. 88, 13689-13698. doi: 10.1128/JVI.02035-14

Kuroki, M., Ariumi, Y., Hijikata, M., Ikeda, M., Dansako, H., Wakita, T., et al. (2013). PML tumor suppressor protein is required for HCV production. Biochem. Biophys. Res. Commun. 430, 592-597. doi: 10.1016/j.bbrc.2012.11.108

Kwong, A. D., Rao, B. G., and Jeang, K. T. (2005). Viral and cellular RNA helicases as antiviral targets. Nat. Rev. Drug Discov. 4, 845-853. doi: 10.1038/nrd1853

Lahn, B. T., and Page, D. C. (1997). Functional coherence of the human Y chromosome. Science 278, 675-680. doi: 10.1126/science.278.5338.675

Lai, M. C., Chang, W. C., Shieh, S. Y., and Tarn, W. Y. (2010). DDX3 regulates cell growth through translational control of cyclin E1. Mol. Cell Biol. 30, 5444-5453. doi: 10.1128/MCB.00560-10

Lai, M. C., Lee, Y. H., and Tarn, W. Y. (2008). The DEAD-box RNA helicase DDX3 associates with export messenger ribonucleoproteins as well as tip-associated protein and participates in translational control. Mol. Biol. Cell 19, 3847-3858. doi: 10.1091/mbc.E07-12-1264

Lai, M. C., Wang, S. W., Cheng, L., Tarn, W. Y., Tsai, S. J., and Sun, H. S. (2013). Human DDX3 interacts with the HIV-1 Tat protein to facilitate viral mRNA translation. PLoS ONE 8:e68665. doi: 10.1371/journal.pone.0068665

Lee, C. H., Lin, S. H., Yang, S. F., Yang, S. M., Chen, M. K., Lee, H., et al. (2014). Low/negative expression of DDX3 might predict poor prognosis in non-smoker patients with oral cancer. Oral Dis. 20, 76-83. doi: 10.1111/odi.12076

Lee, C. S., Dias, A. P., Jedrychowski, M., Patel, A. H., Hsu, J. L., and Reed, R. (2008). Human DDX3 functions in translation and interacts with the translation initiation factor eIF3. Nucleic Acids Res. 36, 4708-4718. doi: 10.1093/nar/gkn454

Leory, P., Alzari, P., Sassoon, D., Wolgemuth, D., and Fellous, M. (1989). The protein encoded by a murine male germ cell-specific transcript is a putative ATPdependent RNA helicase. Cell 57, 549-559. doi: 10.1016/0092-8674(89)90125-6

Li, C., Ge, L. L., Li, P. P., Wang, Y., Dai, J. J., Sun, M. X., et al. (2014a). Cellular DDX3 regulates Japanese encephalitis virus replication by interacting with viral un-translated regions. Virology 449, 70-81. doi: 10.1016/j.virol.2013.11.008

Li, Q., Zhang, P., Zhang, C., Wang, Y., Wan, R., Yang, Y., et al. (2014b). DDX3X regulates cell survival and cell cycle during mouse early embryonic development. J. Biomed. Res. 28, 282-291. doi: 10.7555/JBR.27.20130047

Li, J., Tang, H., Mullen, T. M., Westberg, C., Reddy, T. R., Rose, D. W., et al. (1999). A role for RNA helicase A in post-transcriptional regulation of HIV type 1. Proc. Natl. Acad. Sci. U.S.A. 96, 709-714. doi: 10.1073/pnas.96.2.709

Linder, P. (2008). mRNA export: RNP remodeling by DEAD-box proteins. Curr. Biol. 18, R297-R299. doi: 10.1016/j.cub.2008.02.027

Linder, P., and Lasko, P. (2006). Bent out of shape: RNA unwinding by the DEAD-box helicase Vasa. Cell 125, 219-221. doi: 10.1016/i.cell.2006.03.030

Listenberger, L. L., and Brown, D. A. (2007). Fluorescent detection of lipid droplets and associated proteins. Curr. Protoc. Cell Biol. 35, 24.2.1-24.2.11. doi: 10.1002/0471143030.cb2402s35

Lorgeoux, R. P., Guo, F., and Liang, C. (2012). From promoting to inhibiting: diverse roles of helicases in HIV-1 replication. Retrovirology 9, 79. doi: 10.1186/17424690-9-79

Maga, G., Falchi, F., Garbelli, A., Belfiore, A., Witvrouw, M., Manetti, F., et al. (2008). Pharmacophore modeling and molecular docking led to the discovery of inhibitors of human immunodeficiency virus-1 replication targeting the human cellular aspartic acid-glutamic acid-alanine-aspartic acid box polypeptide 3 . J. Med. Chem. 51, 6635-6638. doi: 10.1021/jm8008844

Maga, G., Falchi, F., Radi, M., Botta, L., Casaluce, G., Bernardini, M., et al. (2011) Toward the discover of novel anti-HIV drug. Second-generation inhibitors of the cellular ATPase DDX3 with improved anti-HIV activity: synthesis, structureactivity relationship analysis, cytotoxicity studies, and target validation. Chem. Med. Chem. 6, 1371-1389. doi: 10.1002/cmdc.201100166

Mamiya, N., and Worman, H. J. (1999). Hepatitis C virus core protein binds to a DEAD box RNA helicase. J. Biol. Chem. 274, 15751-15756. doi: 10.1074/jbc.274.22.15751

Mazeyrat, S., Saut, N., Sargent, C. A., Grimmond, S., Longepied, G., Ehrmann, I. E., et al. (1998). The mouse Y chromosome interval necessary for spermatogonia 
proliferation is gene dense with syntenic homology to the human AZFa region. Hum. Mol. Genet. 7, 1713-1724. doi: 10.1093/hmg/7.11.1713

McGivern, D. R., and Lemon, S. M. (2009). Tumor suppressors, chromosomal instability, and hepatitis C virus-associated liver cancer. Annu. Rev. Pathol. 4, 399-415. doi: 10.1146/annurev.pathol.4.110807.092202

Merz, C., Urlaub, H., Will, C. L., and Lührmann, R. (2007). Protein composition of human mRNPs spliced in vitro and differential requirement for mRNP protein recruitment. RNA 13, 116-128. doi: 10.1261/rna.336807

Meylan, E., Curran, J., Hofmann, K., Moradpour, D., Binder, M., Bartenschlager, R., et al. (2005). Cardif is an adaptor protein in the RIG-1 antiviral pathway and is targeted by hepatitis C virus. Nature 437, 1167-1172. doi: 10.1038/nature 04193

Miao, X., Yang, Z. L., Xiong, L., Zou, Q., Yuan, Y., Li, J., et al. (2013). Nectin2 and DDX3 are biomarkers for metastasis and poor prognosis of squamous cell/adenosquamous carcinomas and adenocarcinoma of gallbladder. Int. J. Clin. Exp. Pathol. 6, 179-190.

Miyanari, Y., Atsuzawa, K., Usuda, N., Watashi, K., Hishiki, T., Zayas, M., et al. (2007). The lipid droplet is an important organelle for hepatitis C virus production. Nat. Cell Biol. 9, 1089-1097. doi: 10.1038/ncb1631

Naji, S., Ambrus, G., Cimermančič, P., Reyes, J. R., Johnson, J. R., Filbrandt, R., et al. (2012). Host cell interactome of HIV-1 Rev includes RNA helicases involved in multiple facets of virus production. Mol. Cell. Proteomics 11, M111.015313. doi: 10.1074/mcp.M111.015313

Oda, S., Schröder, M., and Khan, A. R. (2009). Structural basis for targeting of human RNA helicase DDX3 by poxvirus protein K7. Structure 17, 1528-1537. doi: 10.1016/j.str.2009.09.005

Oshiumi, H., Ikeda, M., Matsumoto, M., Watanabe, A., Takeuchi, O., Akira, S., et al. (2010a). Hepatitis C virus core protein abrogates the DDX3 function that enhances IPS-1-mediated IFN-beta induction. PLOS ONE 5:e14258. doi: 10.1371/journal.pone.0014258

Oshiumi, H., Sakai, K., Matsumoto, M., and Seya, T. (2010b). DEAD/H BOX 3 (DDX3) helicase binds the RIG-I adaptor IPS-1 to up-regulate IFN-beta-inducing potential. Eur. J. Iummunol. 40, 940-948. doi: 10.1002/eji.200940203

Owsianka, A. M., and Patel, A. H. (1999). Hepatitis C virus core protein interacts with a human DEAD box protein DDX3. Virology 257, 330-340. doi: 10.1006/viro.1999.9659

Park, S. H., Lee, S. G., Kim, Y., and Song, K. (1998). Assignment of a human putative RNA helicase gene, DDX3, to human X chromosome bands p11.3--> p11.23. Cytogenet. Cell Genet. 81, 178-179. doi: 10.1159/000015022

Parker, R., and Sheth, U. (2007). P bodies and the control of mRNA trabslation and degradation. Mol. Cell 25, 635-646. doi: 10.1016/j.molcel.2007.02.011

Pollard, V. W., and Malim, M. H. (1998). The HIV-1 Rev protein. Annu. Rev. Microbiol. 52, 491-532. doi: 10.1146/annurev.micro.52.1.491

Radi, M., Falchi, F., Garbelli, A., Samuele, A., Bernardo, V., Paolucci, S., et al. (2012). Discovery of the first small molecule inhibitor of human DDX3 specifically designed to target the RNA binding site: towards the next generation HIV-1 inhibitors. Bioorg. Med. Chem. Lett. 22, 2094-2098. doi 10.1016/j.bmcl.2011.12.135

Randall, G., Panis, M., Cooper, J. D., Tellinghuisen, T. L., Sukhodolets, K. E., Pfeffer, S., et al. (2007). Cellular cofactors affecting hepatitis C virus infection and replication. Proc. Natl. Acad. Sci. U.S.A. 104, 12884-12889. doi: 10.1073/pnas.0704894104

Robertson-Anderson, R. M., Wang, J., Edgcomb, S. P., Carmel, A. B., Williamson, J. R., and Millar, D. P. (2011). Single-molecule studies reveal that DEAD box protein DDX1 promotes oligomerization of HIV-1 Rev on the Rev responsive element J. Mol. Biol. 410, 959-971. doi: 10.1016/j.jmb.2011.04.026

Saito, T., and Gale, M. Jr. (2007). Principles of intracellular viral recognition. Curr. Opin. Immunol. 19, 17-23. doi: 10.1016/j.coi.2006.11.003

Scheller, N., Mina, L. B., Galão, R. P., Chari, A., Giménez-Barcons, M., Noueiry, A., et al. (2009). Translation and replication of hepatitis $C$ virus genomic RNA dependes on ancient cellular proteins that control mRNA fates. Proc. Natl. Acad. Sci. U.S.A. 106, 13517-13522. doi: 10.1073/pnas.0906413106

Schröder, M. (2010). Human DEAD-box protein 3 has multiple functions in gene regulation and cell cycle control and is a prime target for viral manipulation. Biochem. Pharmcol. 79, 297-306. doi: 10.1016/j.bcp.2009.08.032

Schröder, M., Baran, M., and Bowie, A. G. (2008). Viral targeting of DEAD box protein 3 reveals its role in TBK/IKKepsilon-mediated IRF activation. EMBO J. 27, 2147-2157. doi: 10.1038/emboj.2008.143
Sekiguchi, T., Kurihara, Y., and Fukumura, J. (2007). Phosphorylation of threonine 204 of DEAD-box RNA helicase DDX3 by cyclin B/cdc2 in vitro. Biochem. Biophys. Res. Commun. 356, 668-673. doi: 10.1016/j.bbrc.2007.03.038

Seth, R. B., Sun, L., Ea, C. K., and Chen, Z. J. (2005). Identification and characterization of MAVS, a mitochondrial antiviral signaling protein that activates NF-B and IRF3. Cell 122, 669-682. doi: 10.1016/j.cell.2005.08.012

Sharma, A., Awasthi, S., Harrod, C. K., Matlock, E. F., Khan, S., Xu, L., et al. (2007). The Werner syndrome helicase is a cofactor for HIV-1 long terminal repeat transactivation and retroviral replication. J. Biol. Chem. 282, 12048-12057. doi: 10.1074/jbc.M608104200

Shih, J. W., Tsai, T. Y., Chao, C. H., and Wu Lee, Y. H. (2008). Candidate tumor suppressor DDX3 RNA helicase specifically represses cap-dependent translation by acting as an eIF4E inhibitory protein. Oncogene 27, 700-714. doi: 10.1038 /sj.onc. 1210687

Shih, J. W., Wang, W. T., Tsai, T. Y., Kuo, C. Y., Li, H. K., and Wu Lee, Y. H. (2012). Critical roles of RNA helicase DDX3 and its interactions with eIF4E/PABP1 in stress granule assembly and stress response. Biochem. J. 441, 119-1129. doi: 10.1042/BJ20110739

Soto-Rifo, R., Rubilar, P. S., Limousin, T., de Breyne, S., Décimo, D., and Ohlmann, T. (2012). DEAD-box protein DDX3 associates with eIF4F to promote translation of selected mRNAs. EMBO J. 31, 3745-3756. doi: 10.1038/emboj.201 2.220

Soto-Rifo, R., Rubilar, P. S., and Ohlmann, T. (2013). The DEAD-box helicase DDX3 substitutes for the cap-binding protein eIF4E to promote compartmentalized translation initiation of the HIV-1 genomic RNA. Nucleic Acids Res. 41, 62866299. doi: 10.1093/nar/gkt306

Soulat, D., Burckstummer, T., Westermayer, S., Goncalves, A., Bauch, A., Stefanovic, A., et al. (2008). The DEAD-box helicase DDX3X is a critical component of the TANK-binding kinase 1-dependent innate immune response. EMBO J. 27, 2135-2146. doi: 10.1038/emboj.2008.126

Sun, C., Pager, C. T., Luo, G., Sarnow, P., and Cate, J. H. (2010). Hepatitis C virus core-derived peptides inhibit genotype $1 \mathrm{~b}$ viral genome replication via interaction with DDX3X. PLoS ONE 5:e12826. doi: 10.1371/journal.pone.00 12826

Sun, M., Song, L., Li, Y., Zhou, T., and Jope, R. S. (2008). Identification of an antiapoptotic protein complex at death receptors. Cell Death Differ. 15, 18871900. doi: $10.1038 /$ cdd.2008.124

Sun, M., Song, L., Zhou, T., Gillespie, G. Y., and Jope, R. S. (2011). The role of DDX3 in regulating Snail. Biochim. Biophys. Acta 1813, 438-447. doi: 10.1016/j.bbamcr.2011.01003

Sun, M., Zhou, T., Jonasch, E., and Jope, R. S. (2013). DDX3 regulates DNA damageinduced apoptosis and p53 stabilization. Biochem. Biophys. Acta 1833, 1489-1497. doi: 10.1016/j.bbamcr.2013.02.026

Tingting, P., Caiyun, F., Zhigang, Y., Pengyuan, Y., and Zhenghong, Y. (2006). Subproteomic analysis of the cellular proteins associated with the $3^{\prime}$ untranslated region of the hepatitis $\mathrm{C}$ virus genome in human liver cells. Biochem. Biophys. Res. Commun. 347, 683-691. doi: 10.1016/j.bbrc.2006.06.144

Tsai, W. C., and Lloyd, R. E. (2014). Cytoplasmic RNA granules and viral infection. Annu. Rev. Virol. 1, 147-170. doi: 10.1146/annurev-virology-031413-085505

Upadya, M. H., Aweya, J. J., and Tan, Y. J. (2014). Understanding the interaction of hepatitis C virus with host DEAD-box RNA helicases. World J. Gastroenterol. 20, 2913-2926. doi: 10.3748/wjg.v20.i11.2913

Utama, A., Shimizu, H., Hasebe, F., Morita, K., Igarashi, A., Shoji, I., et al. (2000). Role of the $\mathrm{DExH}$ motif of the Japanese encephalitis virus and hepatitis $\mathrm{C}$ virus NS3 proteins in the ATPase and RNA helicase activities. Virology 273, 316-324. doi: $10.1006 /$ viro. 2000.0417

Vashist, S., Urena, L., Chaudhry, Y., and Goodfellow, I. (2012). Identification of RNA-protein interaction networks involved in the norovirus life cycle. J. Virol. 86, 11977-11990. doi: 10.1128/JVI.00432-12

Wakita, T., Pietschmann, T., Kato, T., Date, T., Miyamoto, M., Zhao, Z., et al. (2005). Production of infectious hepatitis $\mathrm{C}$ virus in tissue culture from a cloned viral genome. Nat. Med. 11, 791-796. doi: 10.1038/nm1268

Wang, H., Kim, S., and Ryu, W. S. (2009). DDX3 DEAD-Box RNA helicase inhibits hepatitis B virus reverse transcription by incorporation into nucleocapsids. J. Virol. 83, 5815-5824. doi: 10.1128/JVI.00011-09

Wang, H., and Ryu, W. S. (2010). Hepatitis B virus polymerase blocks pattern recognition receptor signaling via interaction with DDX3: implications for immune evasion. PLoS Pathog. 6:e1000986. doi: 10.1371/journal.ppat.1000986 
Wu, D. W., Lee, M. C., Wang, J., Chen, C. Y., Cheng, Y. W., and Lee, H. (2014). DDX3 loss by p53 inactivation promotes tumor malignancy via the MDM2/Slug/Ecadherin pathway and poor patient outcome in non-small-cell lung cancer. Oncogene 33, 1515-1526. doi: 10.1038/onc.2013.107

Wu, D. W., Liu, W. S., Wang, J., Chen, C. Y., Cheng, Y. W., and Lee, H. (2011). Reduced $\mathrm{p} 21$ (WAF1/CIP1) via alteration of $\mathrm{p} 53-\mathrm{DDX} 3$ pathway is associated with poor relapse-free survival in early-stage human papillomavirus-associated lung cancer. Clin. Cancer Res. 17, 1895-1905. doi: 10.1158/1078-0432.CCR-10-2316

Xu, L. G., Wang, Y. Y., Han, K. J., Li, L. Y., Zhai, Z., and Shu, H. B. (2005). VISA is an adaptor protein required for virus-triggered IFN- signaling. Mol. Cell 19, 727-740. doi: 10.1016/j.molcel.2005.08.014

Yasuda-Inoue, M., Kuroki, M., and Ariumi, Y. (2013a). Distinct DDX DEAD-box RNA helicases cooperate to modulate the HIV-1 Rev function. Biochem. Biophys. Res. Commun. 434, 803-808. doi: 10.1016/j.bbrc.2013.04.016

Yasuda-Inoue, M., Kuroki, M., and Ariumi, Y. (2013b). DDX3 RNA helicase is required for HIV-1 Tat function. Biochem. Biophys. Res. Commun. 441, 607-611. doi: 10.1016/j.bbrc.2013.10.107

Yedavalli, V. S., Neuveut, C., Chi, Y. H., Kleiman, L., and Jeang, K. T. (2004). Requirement of DDX3 DEAD box RNA helicase for HIV-1 Rev-RRE export function. Cell 119, 381-392. doi: 10.1016/j.cell.2004.09.029

Yedavalli, V. S., Zhang, N., Cai, H., Zhang, P., Starost, M. F., Hosmane, R. S., et al. (2008). Ring expanded nucleoside analogues inhibit RNA helicase and intracellular human immunodeficiency virus type 1 replication. J. Med. Chem. 51, 5043-5051. doi: 10.1021/jm800332m

Yoneyama, M., Kikuchi, M., Natsukawa, T., Shinobu, N., Imaizumi, T., Miyagishi, M., et al. (2004). The RNA helicase RIG-I has an essential function in doublestranded RNA-induced innate antiviral response. Nat. Immunol. 5, 730-737. doi: $10.1038 /$ ni1087
You, L. R., Chen, C. M., Yeh, T. S., Tsai, T. Y., Mai, R. T., Lin, C. H., et al. (1999). Hepatitis $\mathrm{C}$ virus core protein interacts with cellular putative RNA helicase. J. Virol. 73, 2841-2853.

Yu, S., Chen, J., Wu, M., Chen, H., Kato, N., and Yuan, Z. (2010). Hepatitis B virus polymerase inhibits RIG-I- and Toll-like receptor 3-mediated beta interferon induction in human hepatocytes through interference with interferon regulatory factor 3 activation and dampening of the interaction between TBK1/IKKepsilon and DDX3. J. Gen. Virol. 91, 2080-2090. doi: 10.1099/vir.0.020552-0

Zhou, X., Luo, J., Mills, L., Wu, S., Pan, T., Geng, G., et al. (2013). DDX5 facilitates HIV-1 replication as a cellular co-factor of Rev. PLoS ONE 8:e65040. doi: 10.1371/journal.pone.0065040

Conflict of Interest Statement: The author declares that the research was conducted in the absence of any commercial or financial relationships that could be construed as a potential conflict of interest.

Received: 30 September 2014; paper pending published: 23 October 2014; accepted: 19 November 2014; published online: 05 December 2014.

Citation: Ariumi Y (2014) Multiple functions of DDX3 RNA helicase in gene regulation, tumorigenesis, and viral infection. Front. Genet. 5:423. doi: 10.3389/fgene.2014.00423 This article was submitted to Genetics of Aging, a section of the journal Frontiers in Genetics.

Copyright (C) 2014 Ariumi. This is an open-access article distributed under the terms of the Creative Commons Attribution License (CC BY). The use, distribution or reproduction in other forums is permitted, provided the original author(s) or licensor are credited and that the original publication in this journal is cited, in accordance with accepted academic practice. No use, distribution or reproduction is permitted which does not comply with these terms. 